University of Wollongong

Research Online

Faculty of Engineering - Papers (Archive)

Faculty of Engineering and Information

Sciences

$1-1-2012$

\title{
Block shear capacity of bolted connections in cold-reduced steel sheets
}

Lip H. Teh

University of Wollongong, Iteh@uow.edu.au

Drew D. A Clements

University of Wollongong, ddac998@uow.edu.au

Follow this and additional works at: https://ro.uow.edu.au/engpapers

Part of the Engineering Commons

https://ro.uow.edu.au/engpapers/4532

\section{Recommended Citation}

Teh, Lip H. and Clements, Drew D. A: Block shear capacity of bolted connections in cold-reduced steel sheets 2012, 459-467.

https://ro.uow.edu.au/engpapers/4532

Research Online is the open access institutional repository for the University of Wollongong. For further information contact the UOW Library: research-pubs@uow.edu.au 


\title{
Block Shear Capacity of Bolted Connections in Cold-Reduced Steel Sheets
}

\author{
Lip H. Teh ${ }^{1}$ A.M.ASCE and Drew D. A. Clements ${ }^{2}$
}

\begin{abstract}
:
This paper examines the mechanisms for block shear failures of bolted connections in steel plates postulated in the design equations specified in the North American, European and Australian steel structures codes. It explains that there is only one feasible mechanism for the limit state of conventional block shear failure, that which involves tensile rupture and shear yielding, irrespective of the steel material ductility. It describes the fundamental shortcomings of various code equations for determining the block shear capacity of a bolted connection. Based on the tensile rupture and shear yielding mechanism, an in-plane shear lag factor, and the active shear resistance planes identified in the present work, this paper proposes a rational equation that is demonstrated to provide more accurate results compared to all the code equations in predicting the block shear capacities of bolted connections in G450 steel sheets subjected to concentric loading. The resistance factor for the proposed equation is computed with respect to the LRFD approach given in the North American specification for the design of cold-formed steel structures.
\end{abstract}

Subject headings: bolted connections, cold-formed steel, shear failures, steel plates, tensile strength

\footnotetext{
${ }^{1}$ Lecturer, School of Civil, Mining \& Environmental Engineering, University Of Wollongong, Wollongong, NSW 2500, AUSTRALIA

${ }^{2}$ Honours Student, School of Civil, Mining \& Environmental Engineering, University Of Wollongong, Wollongong, NSW 2500, AUSTRALIA
} 


\section{Introduction}

Block shear failure is recognised as a strength limit state of bolted connections in the North American Specification for the Design of Cold-formed Steel Structural Members 2007 (AISI 2010) and AS/NZS 4600:2005 Cold-formed Steel Structures (SA/SNZ 4600). However, there has been very little research on block shear failures in cold-formed steel members or coldreduced steel sheets, although Seleim \& LaBoube (1996) published the laboratory test results of three such bolted connections undergoing the limit state of block shear failure.

The varied equations for determining the block shear capacity of a bolted connection specified in the cold-formed steel design codes have been adopted from those found in the AISC specifications (AISC 1993a, 2010a), which in turn have been evolving over the years based on the laboratory test results of bolted connections in hot-rolled steel (Birkemoe \& Gilmor 1978, Ricles \& Yura 1983, Hardash \& Bjorhovde 1985) and their critical assessments (Cunningham et al. 1995, Kulak \& Grondin 2001, Epstein \& Aleksiewicz 2008). As discussed in this paper, all variants of the code equations for determining the block shear capacity of a bolted connection (in flat plates) have certain fundamental shortcomings.

In terms of accuracy in predicting the block shear capacities of bolted connections in hotrolled steel plates tested in laboratories, the code equations were found to produce significant variations from the test results even though they were conservative in many cases (Hardash \& Bjorhovde 1985, Cunningham et al. 1995, Kulak \& Grondin 2001, Driver et al. 2006). Hardash \& Bjorhovde (1985) found that the use of the ultimate shear stress instead of the yield shear stress in predicting the block shear capacities was more accurate for short connections, while the reverse was true for long connections. They proposed an improved equation accounting for the connection (shear) length, which was based on the least squares linear regression analysis of the laboratory test results. Another empirical equation that makes 
use of the connection length, based on a regression analysis of finite element analysis results, was proposed by Topkaya (2004). Similarly, based on statistical optimisations, Cunningham et al. (1995) presented a number of empirical equations that accounted for the aspect ratio of the block, defined as the ratio of the shear plane length to the tension plane length. Driver et al. (2006) simply used the mean between the ultimate tensile strength and the yield stress in computing the shear resistance term of the block shear capacity.

In the literature, evaluations of contesting equations for predicting the block shear capacities of bolted connections have been complicated by the fact that the hot-rolled steel materials used in the experimental tests had high ratios of ultimate strength to yield stress $\left(F_{\mathrm{u}} / F_{\mathrm{y}}\right)$, which often acted as a "saving grace". The median ratio of the specimens studied by Birkemoe \& Gilmor (1978), Ricles \& Yura (1983) and Hardash \& Bjorhovde (1985) was greater than 1.55. Such high ratios of ultimate tensile strength to yield stress are not possessed by cold-reduced sheet steels (Seleim \& LaBoube 1996, Rogers \& Hancock 1998, Hancock 2007).

On the other hand, the net section tension strength between bolt holes in a cold-reduced steel sheet is affected by in-plane shear lag (Chong \& Matlock 1975, Teh \& Gilbert 2011), which does not appear to be the case with bolted connections in hot-rolled steel plates (Kulak \& Grondin 2001) although Cunningham et al. (1995) argued that the use of the full net section tension area was not warranted for many (hot-rolled steel plate) bolted connections. As explained later, block shear failure of a bolted connection invariably involves tensile rupture.

This paper is concerned with the study of block shear failures of bolted connections, subjected to concentric loading only in order to exclude the effects caused by eccentricities discussed by Epstein \& Aleksiewicz (2008). It provides a critique of legacy and current code equations for determining the block shear capacity of a bolted connection, and discusses the 
mechanisms for block shear failures postulated in the literature and anticipated in the design codes. It also identifies the active shear resistance planes of a bolted connection block.

Based on the mechanism identified as the only feasible one and the limit state of block shear failure defined in the present work, the paper presents a rational equation that incorporates a shear lag factor and accurately predicts the block shear capacities of bolted connections in cold-reduced steel sheets with low ratios of ultimate strength to yield stress, which are tested in the present work. The use of such low ductility steels in the experiment enables the implication of using the gross area in computing the shear yield resistance to be studied.

This paper does not cover the type of block shear failure in which two outer regions of the connected parts displace together from the remainder parts (the "split" block shear failure).

\section{Code equations for block shear capacity}

Clause 5.6.3 of AS/NZS 4600:2005 Cold-formed Steel Structures (SA/SNZ 2005) specifies the nominal block shear capacity $P_{\mathrm{p}}$ of a bolted connection to be

a) For $F_{u} A_{n t} \geq 0.6 F_{u} A_{n v}: P_{p}=F_{u} A_{n t}+0.6 F_{y} A_{g v}$

b) For $F_{u} A_{n t} \leq 0.6 F_{u} A_{n v}: P_{p}=0.6 F_{u} A_{n v}+F_{y} A_{g t}$

in which $F_{\mathrm{u}}$ is the material tensile strength, $F_{\mathrm{y}}$ is the yield stress, $A_{\mathrm{nt}}$ is the net tensile area, $A_{\mathrm{gv}}$ is the gross shear area, $A_{\mathrm{nv}}$ is the net shear area, and $A_{\mathrm{gt}}$ is the gross tensile area. The regions corresponding to these areas as defined by the code are shown in Figure 1.

Equation (1a) represents block shear failure by the tensile rupture and shear yielding mechanism, while Equation (1b) anticipates the shear rupture and tensile yielding mechanism. The clause is adopted from Section J4.3 of the 1993 AISC LRFD Specification 
for Structural Steel Buildings (AISC 1993a), which in turn resulted from an amendment to the block shear capacity specified in the 1986 AISC LRFD specification (AISC 1986), being

$$
P_{p}=\max (\text { Equation (1a); Equation (1b)) }
$$

The rationale for Equation (2), which is counter-intuitive, was given in the commentary to the 1993 specification (AISC 1993b) by way of two extreme examples, which are illustrated in Figure 2. For the connection with a high aspect ratio shown in Figure 2(a), Equation (1a) gives a lower capacity than Equation (1b). However, considering the total force is resisted primarily by shear, the commentary argued that shear rupture, not shear yielding, should control the block shear failure mode and therefore Equation (1b) should be used. For the connection with a low aspect ratio shown in Figure 2(b), Equation (1b) gives a lower capacity than Equation (1a). However, the commentary argued that since block shear failure cannot occur until the net section ruptures, Equation (1a) should be used.

It was further argued in the commentary that since block shear failure was a rupture or tearing phenomenon, not a yielding one, the proper equation to use was the one with the larger rupture term, as formalised by Equation (1). The commentary appears to miss the fact that Equations (1) and (2) do not always lead to the same outcome, especially for a connection with a low ratio of tensile strength to yield stress (Epstein 1996) and multiple rows of bolts.

In any case, both the 1986 and the 1993 AISC LRFD specifications ignore the fact that the tensile resistance component of Equation (1b) is not available when shear rupture occurs, which can only follow tensile rupture. Published laboratory test results (Birkemoe \& Gilmor 1978, Ricles \& Yura 1983, Hardash \& Bjorhovde 1985, Seleim \& LaBoube 1996, Kuwamura \& Isozaki 2002, Huns et al. 2006) have shown that block shear failures invariably involve tensile rupture, whether the maximum load is reached due to tensile rupture or shear rupture. 
It is also explained in the next section that a block shear failure cannot normally be caused by the shear rupture and tensile yielding mechanism postulated in Equation (1b).

The nominal block shear capacity was amended again in the 2005 specification (AISC 2005a), and remains in the current specification (AISC 2010a). The commentary (AISC 2005b, AISC 2010b) states that block shear failure is a rupture or tearing phenomenon, not a yielding one, and hence the block shear capacity should be primarily computed from

$$
P_{p}{ }^{\prime}=F_{u} A_{n t}+0.6 F_{u} A_{n v}
$$

provided the computed capacity does not exceed that given by Equation (1a), or

$$
P_{p}=\min (\text { Equation (1a); Equation (3)) }
$$

Equation (3) is in fact the nominal block shear capacity specified in the earlier AISC ASD specifications (AISC 1978, 1989). As explained in the next section, the mechanism implied by this equation, that the block shear failure occurs by simultaneous tensile and shear ruptures, is not generally feasible. This fact was the reason why Equation (3) specified in the 1978 specification was then amended to Equation (2) in the 1986 specification (AISC 1986).

Equation (4) points to the awkwardness of using the gross area in computing the shear yield resistance, as it implies that a larger force could be required to cause a block shear failure by the tensile rupture and shear yielding mechanism than by the simultaneous tensile and shear ruptures mechanism, contrary to the fact that shear yielding must precede shear rupture. It will be seen that both Equations (1a) and (1b) give significantly higher capacities than Equation (3) for all specimens tested in the present work.

The commentaries (AISC 1993b, AISC 2010b) argue that the use of the gross areas in Equation (1) for calculating the shear and tensile yield resistance components is consistent 
with the use of the gross area in determining the limit state of yielding of a tension member. However, in reality, the gross areas are not wholly available for resistance.

Yielding of the region surrounding a net section of a tension member is simply not considered to be a limit state. Yielding of the gross section along the member that leads to excessive member elongation is considered to be a strength limit state, as is the fracture of a net section. There is no consistency for using the gross areas in calculating the yield resistances in Equation (1) as they are not wholly available for resisting block shear failure.

In any case, Equation (4) is also specified in Section E5.3 of Supplement No. 2 to the North American Specification for the Design of Cold-Formed Steel Structural Members (AISI 2010). It may be noted that the 1999 AISC LRFD specification (AISC 1999) specifies

$$
P_{p}=\min (\text { Equation (1); Equation (3)) }
$$

A more rational equation for the nominal block shear capacity $P_{\mathrm{p}}$ is specified in Eurocode 3

Part 1.8 (ECS 2005)

$$
P_{p}=F_{u} A_{n t}+F_{y} A_{n v} / \sqrt{3}=F_{u} A_{n t}+0.577 F_{y} A_{n v}
$$

where the net shear area $A_{\mathrm{nv}}$ as indicated in Figure 1 is used for calculating the shear yield resistance based on the von Mises yield criterion, replacing the use of the gross shear area in the earlier specification (ECS 1992).

\section{Mechanisms for block shear failures}

Consider the connected end of a flat member shown in Figure 3 that is subjected to a concentric load and is restrained from out-of-plane failure modes. Leaving out the pure net section tension failure mode and the bearing failure mode from the present discussion, there 
are essentially only two possible failure modes for the connected end. If the connection shear length (which is equal to the distance $e_{\mathrm{n}}$ in Figure 3 ) is relatively short, it will fail by "shear out" of each bolt, a distinct failure mode illustrated in Figure 4(a). In the present work, the shear out failure mode is distinguished from the bearing failure mode shown in Figure 4(b), even though they are both treated as bearing failure in the AISC specification (AISC 2010a).

Section E5.1 of Supplement No. 2 to the North American Specification for the Design of Cold-Formed Steel Structural Members (AISI 2010) specifies the shear out capacity $P_{\text {sop }}$ of the two-bolt connection in Figure 3 to be

$$
P_{\text {sop }}=0.6 F_{u} A_{n v}=2.4 F_{u} t e_{n}
$$

in which $t$ is the thickness of the sheet.

It could be imagined that as the connection shear length $e_{\mathrm{n}}$ increases, or as the bolt spacing decreases, or both, any of which results in an increase of the aspect ratio, a condition would be reached such that it is conceivable for the connected end to undergo block shear failure by simultaneous tensile and shear ruptures postulated in Equation (3). The aspect ratio at which the hypothetical mechanism of simultaneous tensile and shear ruptures could occur is termed the threshold ratio in the present work.

In reality, a conventional block shear failure by the simultaneous tensile and shear ruptures mechanism postulated in Equation (3) is not generally feasible. Once yielding around the perimeter of the block takes place and the block displaces as a whole, the tensile strains in the net section between bolt holes increase much more rapidly than the shear strains as the former cannot be redistributed while the latter relax relative to the former (note the arching in Figure 4c) so that the block eventually fails by tensile rupture and shear yielding. 
Even at an aspect ratio that is slightly lower than the threshold ratio, a block shear failure by tensile rupture and shear yielding is still possible as shown in Figure 5, where the shear-out deformations were over-run by the tensile rupture and shear yielding mechanism. The change-over in the failure mode took place when yielding started in the tensile net section between the two bolt holes, where tensile rupture eventually took place.

As the aspect ratio increases beyond the threshold ratio, block shear failure can only be due to tensile rupture and shear yielding since the tensile strains are always more critical than the shear strains. An example of such a failure mode is shown in Figure 4(c), where tensile rupture took place in the net section between the two bolt holes. This theoretical exposition is borne out by extensive experimental tests (Hardash \& Bjorhovde 1985, Cunningham et al. 1995, Seleim \& LaBoube 1996, Huns et al. 2006).

Obviously, at an aspect ratio that is sufficiently lower than the threshold ratio, the shear-out failure mode governs. There is therefore no aspect ratio at which a block shear failure occurs by the shear rupture and tensile yielding mechanism postulated in Equation (1b).

The present exposition does not account for the situation in which bolt hole deformations are such that shear rupture could precede tensile rupture. However, for the specimens tested by Seleim \& LaBoube (1996) in which the bearing failure took place before the block shear failure, the mechanism was still tensile rupture and shear yielding. In these cases, the strength limit state was bearing failure rather than block shear failure. (It was not possible for the bearing failures to have followed the block shear failures, but the opposite must have ensued when the tests were continued well past the ultimate bearing capacities, resulting in the reduction of the shear resistance area of each block.)

\section{Proposed equation for block shear failure in cold-reduced steel}




\section{The strength limit state of block shear failure}

As explained in the preceding section, among the various mechanisms postulated in the literature for conventional block shear failures, there is only one feasible mechanism, that which involves tensile rupture and shear yielding. In this mechanism, as the block displaces, the tensile strains at the last row of bolts from the free end increase with the applied load until necking occurs in the critical net section(s). With continuing displacements of the block, the tensile strains keep increasing but at one point the applied load has to decrease to maintain static equilibrium due to the necked tension area. The point at which the applied load has to decrease is the limit load identified in Figure 6. When the tensile strain adjacent to a bolt hole reaches the critical value, fracture propagates away from the bolt hole across the tensile net section, causing an abrupt drop in the resistance as shown in Figure 6 for a specimen tested in the present work.

It is possible for a connection with a very high aspect ratio in which the shear resistance dominates to undergo a second limit load following the tensile rupture that is higher than the first limit load. However, for the purpose of the present work, the block shear capacity of a bolted connection is defined as the maximum load preceding the tensile rupture, as represented by the limit load in Figure 6.

\section{Material and geometric properties for determining the block shear capacity}

In the literature, evaluations of contesting equations for determining the block shear capacities of bolted connections have been somewhat clouded by two offsetting factors:

1. All specimens tested in the laboratories were composed of steel materials having high ratios of ultimate strength to yield stress $\left(F_{\mathrm{u}} / F_{\mathrm{y}}\right)$, with a median ratio of greater than 1.55 for the specimens studied by Birkemoe \& Gilmor (1978), Ricles \& Yura (1983) 
and Hardash \& Bjorhovde (1985). The lowest ratio was 1.30 (for one $6.4 \mathrm{~mm}$ thick cold-rolled steel specimen mistakenly used in the test program by Hardash \& Bjorhovde 1985), and the highest was 1.75 . The steel material recently used by Huns et al. (2006) had a ratio of 1.33. Since shear strain hardening may precede a block shear failure, the use of the yield stress in the evaluated equations for computing the shear yield resistance tends to underestimate its contribution.

2. Most evaluated equations use the gross area for computing the yield resistance component of a block shear capacity. Since in reality the gross area is not wholly available, such an approach tends to overestimate the yielding resistance.

As the two factors may offset each other, Equation (1a) was often found to provide the most reasonable (albeit significantly varied) results compared to the other evaluated equations.

Hardash \& Bjorhovde (1985) found that for connections with low aspect ratios, the use of the following equation

$$
P_{p}=F_{u} A_{n t}+F_{u} A_{g v} / \sqrt{3}=F_{u} A_{n t}+0.577 F_{u} A_{g v}
$$

led to overestimations of less than $10 \%$ only while Equation (1a) led to underestimations of much larger magnitudes. For such connections, at the strength limit state most of the block shear stresses were well into the strain hardening range close to the ultimate shear stress.

Conversely, Hardash \& Bjorhovde (1985) found that the substitution of the yield stress $F_{\mathrm{y}}$ for the ultimate strength $F_{\mathrm{u}}$ in the shear resistance term of Equation (8) led to more reasonable estimates for connections with high aspect ratios. At the strength limit state of such connections, most of the block shear stresses were closer to the yield shear stress. 
For the sake of conservatism and simplicity, the present work uses the yield stress in determining the shear resistance component of the block shear capacity. For cold-reduced high-strength sheet steels including the G450 steel materials used in the present work, the ratio of ultimate tensile strength to yield stress can be significantly below 1.10 .

Based on the authors' finite element analysis results (Clements \& Teh 2011) and the experimental evidence of Franchuk et al. (2003), the lengths of the shear and tensile planes resisting a block shear failure are indicated in Figure 7.

\section{The proposed equation}

Based on the preceding expositions and the conclusion of Teh \& Gilbert (2011), the block shear capacity of a bolted connection in cold-reduced steel sheet should be computed from

$$
P_{p}=0.6 F_{y} A_{a v}+F_{u} \sum A_{n t}\left(0.9+0.1 d / p_{2}\right)
$$

in which the active shear area $A_{\mathrm{av}}$ is determined from the length of the active shear planes shown in Figure 7. The variable $d$ denotes the bolt diameter and $p_{2}$ the bolt spacing in the tensile resistance plane. For a connection with multiple rows of bolts, the active shear area $A_{\text {av }}$ is therefore different from the net shear area $A_{\text {nv }}$ defined in the steel design codes.

\section{Test materials}

The G450 sheet steel materials used in the laboratory tests, which have a trade name GALVASPAN $^{\circledR}$, were manufactured and supplied by Bluescope Steel Port Kembla Steelworks, Australia. Two nominal thicknesses were used in the present work, being $1.5 \mathrm{~mm}$ and $3.0 \mathrm{~mm}$. The average base metal thicknesses $t_{\text {base, }}$ yield stresses $F_{\mathrm{y}}$, tensile strengths $F_{\mathrm{u}}$ and elongations at fracture over $15 \mathrm{~mm}, 25 \mathrm{~mm}$ and $50 \mathrm{~mm}$ gauge lengths $\varepsilon_{15}, \varepsilon_{25}$ and $\varepsilon_{50}$, and 
uniform elongation outside the fracture $\varepsilon_{\text {uo }}$ of the steel materials as obtained from six 12.5 $\mathrm{mm}$ wide tension coupons are shown in Table 1. Tensile loading of all coupons and bolted connection specimens is in the direction transverse to the rolling direction of the G450 sheet steel. The tension coupon tests were conducted at a constant stroke rate of $1 \mathrm{~mm} / \mathrm{minute}$ resulting in a strain rate of about $2 \times 10^{-4}$ per second prior to necking.

Table 1 Average material properties

\begin{tabular}{ccccccccc}
\hline & $\begin{array}{c}\boldsymbol{t}_{\text {base }} \\
(\mathbf{m m})\end{array}$ & $\begin{array}{c}\boldsymbol{F}_{\mathbf{y}} \\
(\mathbf{M P a})\end{array}$ & $\begin{array}{c}\boldsymbol{F}_{\mathbf{u}} \\
(\mathbf{M P a})\end{array}$ & $\boldsymbol{F}_{\mathbf{u}} / \boldsymbol{F}_{\mathbf{y}}$ & $\begin{array}{c}\boldsymbol{\varepsilon}_{15} \\
(\mathbf{\%})\end{array}$ & $\begin{array}{c}\boldsymbol{\varepsilon}_{\mathbf{2 5}} \\
(\mathbf{\%})\end{array}$ & $\begin{array}{c}\boldsymbol{\varepsilon}_{\mathbf{5 0}} \\
\mathbf{( \% )}\end{array}$ & $\begin{array}{c}\boldsymbol{\varepsilon}_{\mathbf{u o}} \\
(\mathbf{\%})\end{array}$ \\
\hline $1.5 \mathrm{~mm}$ & 1.48 & 605 & 630 & 1.04 & 21.3 & 18.0 & 12.0 & 6.8 \\
$3.0 \mathrm{~mm}$ & 2.95 & 530 & 580 & 1.09 & 29.3 & 22.0 & 15.3 & 8.1 \\
\hline
\end{tabular}

The tensile strengths in the direction transverse to the rolling direction of $1.5 \mathrm{~mm}$ and $3.0 \mathrm{~mm}$ G450 sheet steels obtained in the present work, rounded to the nearest $5 \mathrm{MPa}$, are $6 \%$ and $10 \%$ higher than those obtained by Teh \& Hancock (2005) in the rolling direction. While Teh \& Hancock (2005) did not provide the ratios of ultimate tensile strength to yield stress, it is believed that the transverse direction is associated with lower ratios. Any errors or offsetting effects arising from the neglect of strain hardening in Equation (9) are thus minimised.

\section{Specimen configurations and test arrangements}

Two connection series were tested in order to investigate the accuracy of the code and proposed equations in predicting the block shear capacities of simple bolted connections in $1.5 \mathrm{~mm}$ and $3.0 \mathrm{~mm} \mathrm{G} 450$ sheet steels. Series A comprised connections having a single row of two bolts, and Series B connections having two such rows, as shown in Figure 8. For each series of a given sheet thickness, $12 \mathrm{~mm}$ and $16 \mathrm{~mm}$ bolts were used. The bolt holes were nominally $1 \mathrm{~mm}$ larger than the corresponding nominal bolt diameters. The bolts were only installed by hand with minimal tightening, and no washers were used in all the tests. 
All specimens were subjected to concentric loading as illustrated in Figure 9 to exclude the effects of eccentric loading on the present study. The critical component is the inner sheet. For the purpose of ensuring that the connected sheets remained vertical throughout the tensile test, a shim plate of the same thickness as the sheet was welded to one of the outer sheets.

The bolted sheets were gripped in such a way that prevented them from rotating in-plane. There was therefore no in-plane eccentricity of the tension load. The bolted connection specimens were tested to failure using an Instron 8033 universal testing machine at a stroke rate of $1 \mathrm{~mm} /$ minute, which coincides with that used for the present tension coupon tests. In the vicinity of the ultimate load associated with net section fracture, the elongation of either a bolted connection specimen or a tension coupon is concentrated in the yielded and necked regions. Therefore, the stroke rate used in determining the ultimate test load $P_{\mathrm{t}}$ of a bolted connection specimen should not ideally be greater than that used in determining the material tensile strength $F_{\mathrm{u}}$, even though the overall length of the former is many times greater. A greater strain rate leads to a higher implied tensile strength (Kassar \& Yu 1992).

\section{Experimental test results and discussions}

In calculating the block shear capacity $P_{\mathrm{p}}$ of a specimen predicted by design equations, the measured values of the geometric dimensions such as the base metal thickness, the bolt hole diameter and the bolt spacing were used. However, for ease of comparisons, only the nominal values are shown in the tables following.

Table 2 lists the relevant geometric dimensions and the test results of Series A specimens (see Figure 8a for an example) which underwent the block shear failure mode. All of them duly failed by the tensile rupture and shear yielding mechanism. The variable $W$ denotes the total sheet width, and $d_{\mathrm{h}}$ the nominal bolt hole diameter. Other variables are defined in Figure 10. 
Table 2 Results of Series A specimens

\begin{tabular}{|c|c|c|c|c|c|c|c|c|c|c|}
\hline \multirow{2}{*}{ Spec } & \multirow{2}{*}{$\begin{array}{c}W \\
(\mathrm{~mm})\end{array}$} & \multirow{2}{*}{$\begin{array}{c}p_{2} \\
(\mathbf{m m})\end{array}$} & \multirow{2}{*}{$\begin{array}{c}t \\
(\mathbf{m m})\end{array}$} & \multirow{2}{*}{$\begin{array}{c}e_{1} \\
(\mathrm{~mm})\end{array}$} & \multirow{2}{*}{$\begin{array}{c}d_{\mathrm{h}} \\
(\mathrm{mm})\end{array}$} & \multicolumn{5}{|c|}{$\boldsymbol{P}_{\mathrm{t}} / \boldsymbol{P}_{\mathrm{p}}$} \\
\hline & & & & & & (1a) & (1b) & (3) & (6) & (9) \\
\hline CPD14 & 100 & 33 & 1.5 & 50 & 17 & 0.80 & 0.72 & 0.90 & 0.95 & 0.95 \\
\hline CPD15 & 100 & 33 & 3.0 & 50 & 13 & 0.90 & 0.82 & 0.93 & 1.02 & 1.01 \\
\hline CPD16 & 100 & 33 & 3.0 & 50 & 17 & 0.89 & 0.79 & 0.96 & 1.06 & 1.04 \\
\hline CPD18 & 120 & 40 & 1.5 & 50 & 17 & 0.86 & 0.79 & 0.96 & 1.01 & 1.00 \\
\hline CPD19 & 120 & 40 & 3.0 & 50 & 13 & 0.90 & 0.83 & 0.93 & 1.01 & 1.01 \\
\hline CPD20a & 120 & 40 & 3.0 & 50 & 17 & 0.93 & 0.84 & 0.99 & 1.08 & 1.07 \\
\hline CPD20b & 120 & 40 & 3.0 & 50 & 17 & 0.93 & 0.84 & 0.98 & 1.07 & 1.07 \\
\hline CPD22a & 100 & 26 & 1.5 & 50 & 17 & 0.81 & 0.72 & 0.93 & 0.99 & 0.96 \\
\hline CPD22b & 100 & 26 & 1.5 & 50 & 17 & 0.83 & 0.74 & 0.95 & 1.02 & 0.99 \\
\hline CPD23a & 100 & 26 & 3.0 & 50 & 13 & 0.90 & 0.80 & 0.93 & 1.03 & 1.01 \\
\hline CPD23b & 100 & 26 & 3.0 & 50 & 13 & 0.89 & 0.80 & 0.93 & 1.02 & 1.01 \\
\hline CPD24a & 100 & 26 & 3.0 & 50 & 17 & 0.87 & 0.76 & 0.94 & 1.05 & 1.02 \\
\hline CPD24b & 100 & 26 & 3.0 & 50 & 17 & 0.87 & 0.76 & 0.94 & 1.05 & 1.02 \\
\hline CPD26a & 120 & 26 & 1.5 & 50 & 17 & 0.85 & 0.76 & 0.97 & 1.03 & 1.01 \\
\hline CPD26b & 120 & 26 & 1.5 & 50 & 17 & 0.84 & 0.75 & 0.96 & 1.02 & 1.00 \\
\hline CPD27 & 120 & 26 & 3.0 & 50 & 13 & 0.91 & 0.81 & 0.94 & 1.04 & 1.02 \\
\hline CPD28a & 120 & 26 & 3.0 & 50 & 17 & 0.91 & 0.79 & 0.98 & 1.09 & 1.06 \\
\hline CPD28b & 120 & 26 & 3.0 & 50 & 17 & 0.89 & 0.77 & 0.96 & 1.07 & 1.04 \\
\hline \multirow[t]{2}{*}{ CPD36 } & 130 & 45 & 3.0 & 30 & 17 & 0.94 & 0.86 & 1.05 & 1.11 & 1.13 \\
\hline & & & & & $/ P$ & 0.88 & 0.79 & 0.95 & 1.04 & 1.02 \\
\hline
\end{tabular}

Table 2 shows the ratios of the ultimate test load $P_{\mathrm{t}}$ to the block shear capacity $P_{\mathrm{p}}$ predicted by Equations (1a), (1b), (3), (6) and (9). As explained in the preceding sections, Equations (1b) and (3) do not represent the true mechanism of block shear failures. 
It can be seen from Table 2 that Equation (1a), which is widely used in the various design codes for determining the ultimate load due to the tensile rupture and shear yielding mechanism, consistently and significantly overestimates the block shear capacities of Series A specimens. Equation (6), specified in Eurocode 3 (ECS 2005), on the other hand, is almost as good as the proposed Equation (9) in determining the block shear capacities of this series.

Equation (1b), which postulates the mechanism of shear rupture and tensile yielding, overestimates the capacity of some specimens by almost $40 \%$. It can also be surmised from the results of Equations (1a) and (1b) that Equation (1) specified in the current Australasian cold-formed steel standard (SA/SNZ 2005) is unconservative for Series A specimens.

Equation (3), given in the current AISC and AISI specifications (AISC 2010, AISI 2010), overestimates the block shear capacities by up to $10 \%$ "only". However, it should be noted that this equation postulates the incorrect mechanism of simultaneous tensile and shear ruptures, while all the specimens failed by the tensile rupture and shear yielding mechanism.

Table 3 shows the outcomes for Series B specimens (see Figure 8b for an example) which underwent the block shear failure mode. All of them duly failed by the tensile rupture and shear yielding mechanism.

As is the case with Series A specimens, Equations (1a) and (1b), and therefore Equation (1), consistently and significantly overestimates the block shear capacities of Series B specimens. The major reason is the use of the gross area in computing the tensile or shear yielding resistance component of the block shear capacity. This effect is likely to have been hidden to various extent in the experimental tests of bolted connections in hot-rolled steel plates by considerable strain hardening due to the very high ratios of ultimate tensile strength to yield 
stress $\left(F_{\mathrm{u}} / F_{\mathrm{y}}\right)$. In certain cases, it might have also been hidden by the higher strain rates incurred during the bolted connection tests compared to the tension coupon tests.

Table 3 Results of Series B specimens $\left(p_{1}=30 \mathrm{~mm}\right)$

\begin{tabular}{|c|c|c|c|c|c|c|c|c|c|c|}
\hline \multirow{2}{*}{ Spec } & \multirow{2}{*}{$\begin{array}{c}W \\
(\mathrm{~mm})\end{array}$} & \multirow{2}{*}{$\begin{array}{c}p_{2} \\
(\mathbf{m m})\end{array}$} & \multirow{2}{*}{$\begin{array}{c}t \\
(\mathrm{~mm})\end{array}$} & \multirow{2}{*}{$\begin{array}{c}e_{1} \\
(\mathrm{~mm})\end{array}$} & \multirow{2}{*}{$\begin{array}{c}d_{\mathrm{h}} \\
(\mathrm{mm})\end{array}$} & \multicolumn{5}{|c|}{$\boldsymbol{P}_{\mathrm{t}} / \boldsymbol{P}_{\mathrm{p}}$} \\
\hline & & & & & & (1a) & (1b) & (3) & (6) & (9) \\
\hline CQ2a & 120 & 26 & 1.5 & 50 & 17 & 0.73 & 0.82 & 1.01 & 1.08 & 0.92 \\
\hline $\mathrm{CQ}^{2 \mathrm{~b}}$ & 120 & 26 & 1.5 & 50 & 17 & 0.74 & 0.84 & 1.02 & 1.09 & 0.93 \\
\hline CQ3 & 120 & 26 & 3.0 & 50 & 13 & 0.85 & 0.89 & 1.00 & 1.12 & 1.00 \\
\hline CQ4 & 120 & 26 & 3.0 & 50 & 17 & 0.80 & 0.86 & 1.02 & 1.15 & 0.99 \\
\hline CQ5a & 130 & 40 & 1.5 & 30 & 13 & 0.82 & 0.91 & 1.04 & 1.10 & 0.99 \\
\hline CQ5b & 130 & 40 & 1.5 & 30 & 13 & 0.81 & 0.89 & 1.02 & 1.08 & 0.98 \\
\hline CQ6a & 130 & 40 & 1.5 & 30 & 17 & 0.77 & 0.88 & 1.08 & 1.14 & 0.98 \\
\hline CQ6b & 130 & 40 & 1.5 & 30 & 17 & 0.77 & 0.88 & 1.09 & 1.14 & 0.99 \\
\hline CQ7 & 130 & 40 & 3.0 & 30 & 13 & 0.89 & 0.96 & 1.07 & 1.17 & 1.07 \\
\hline CQ8 & 130 & 40 & 3.0 & 30 & 17 & 0.83 & 0.94 & 1.13 & 1.22 & 1.06 \\
\hline CQ9b & 130 & 55 & 1.5 & 30 & 13 & 0.81 & 0.89 & 1.00 & 1.04 & 0.97 \\
\hline CQ10a & 130 & 55 & 1.5 & 30 & 17 & 0.78 & 0.89 & 1.04 & 1.08 & 0.98 \\
\hline CQ10b & 130 & 55 & 1.5 & 30 & 17 & 0.80 & 0.90 & 1.06 & 1.10 & 1.00 \\
\hline CQ11 & 130 & 55 & 3.0 & 30 & 13 & 0.87 & 0.94 & 1.02 & 1.09 & 1.03 \\
\hline \multirow[t]{2}{*}{ CQ12 } & 130 & 55 & 3.0 & 30 & 17 & 0.85 & 0.96 & 1.10 & 1.17 & 1.06 \\
\hline & & & & & & 0.81 & 0.90 & 1.05 & 1.12 & 1.00 \\
\hline
\end{tabular}

In contrast to the outcome for Series A specimens, Equation (6) now underestimates the block shear capacities significantly, by almost $20 \%$ for specimen CQ8. Equation (3), which postulates the simultaneous tensile and shear ruptures mechanism, also predicts lower capacities than the proposed Equation (9). The conservatism is the use of an over-reduced shear area in Equations (6) and (3), and increases with increasing number of bolt rows as the 
difference between the net and the active shear areas widens while the shear resistance becomes more important relative to the tensile resistance.

Equation (9), in conjunction with the active resistance planes defined in Figure 7, predicts the block shear capacities of Series A and B specimens with the greatest accuracy. The overall average ratio of the ultimate test load $P_{\mathrm{t}}$ to the block shear capacity $P_{\mathrm{p}}$ predicted by the proposed equation is 1.01 , with a standard deviation of 0.044 .

It may be noted that, if the yield stress $F_{\mathrm{y}}$ in Equation (9) is replaced with the mean between the ultimate tensile strength $F_{\mathrm{u}}$ and the yield stress to account for strain hardening, then the average $P_{\mathrm{t}} / P_{\mathrm{p}}$ ratio will be 0.99 with a standard deviation of 0.036 .

\section{Resistance factor (or capacity reduction factor)}

The relative reliability of structural design rules including the design equations for connections is described in terms of a reliability index, commonly denoted $\beta$. A larger value of $\beta$ indicates a greater reliability. The target reliability index $\beta_{0}$ for a connection is 3.5 , which is recommended in Section F1.1 of the North American specification (AISI 2007) and in the commentary to Clause 1.6.2.2 of the Australasian code (SA/SNZ 1998).

Section F1.1 of the North American specification (AISI 2007) specifies that the resistance factor $\phi$ of a design equation is determined as follows

$$
\phi=C_{\phi}\left(M_{m} F_{m} P_{m}\right) e^{p}
$$

in which $C_{\phi}$ is the calibration coefficient equal to 1.52 in the case of the Load and Resistance Factor Design (LRFD), $M_{\mathrm{m}}$ is the mean value of the material factor equal to 1.187 in the present case, $F_{\mathrm{m}}$ is the mean value of the fabrication factor equal to 0.99 , and $P_{\mathrm{m}}$ is the mean value of the professional factor equal to 1.01 as stated in the preceding section. The statistical 
parameters of the material and fabrication factors of the (unwelded) $1.5 \mathrm{~mm}$ and $3.0 \mathrm{~mm}$ G450 sheet steels have been previously provided by Teh \& Hancock (2005).

The power $p$ of the natural logarithmic base $e$ in Equation (10) is

$$
p=-\beta_{0} \sqrt{V_{M}^{2}+V_{F}^{2}+C_{p} V_{P}^{2}+V_{Q}^{2}}
$$

in which $V_{\mathrm{M}}$ is the coefficient of variation of the material factor equal to 0.03 in the present case, $V_{\mathrm{F}}$ is the coefficient of variation of the fabrication factor equal to $0.02, V_{\mathrm{P}}$ is the coefficient of variation of the professional factor equal to 0.065 being the minimum value specified in Section F1.1 of the specification, $C_{\mathrm{p}}$ is the correction factor equal to 1.09 as computed from the relevant equation given in Section F1.1, and $V_{\mathrm{Q}}$ is the coefficient of variation of load effects equal to 0.21 as specified in Section F1.1.

It was found that in order to achieve the target reliability index $\beta_{0}$ of 3.5 in the LRFD, Equation (10) yields a resistance factor of 0.83. A resistance factor $\phi$ equal to 0.80 (rounded down to the nearest 0.05 ) in conjunction with Equation (9) is therefore recommended. This value is higher than the current value of 0.65 specified in the cold-formed steel design codes (AISI 2007, SA/SNZ 2005), reflecting the greater reliability of the proposed Equation (9) compared to Equations (1) and (4).

\section{Conclusions}

It has been pointed out that, among the various mechanisms for conventional block shear failures postulated in the literature and anticipated in the design codes, there is only one feasible mechanism, that which involves tensile rupture and shear yielding. The physical reasoning presented in the paper explains why extensive published laboratory tests have never found a block shear failure caused by any other mechanisms. 
It has also been pointed out that, excluding the pure net section tension failure mode and the bearing failure mode, the shear-out failure mode governs the strength limit state of bolted connections with low aspect ratios of the block. At higher ratios, the block shear failure is enabled by the tensile rupture and shear yielding mechanism only.

The equation given in the current AISC and AISI specifications which postulates the simultaneous tensile and shear ruptures mechanism overestimates the block shear capacities of the single-row bolted connections, but underestimates those of the double-row bolted ones. The equation specified in the current European steel structures code, which correctly anticipates the tensile rupture and shear yielding mechanism, significantly underestimates the block shear capacities of the double-row bolted connection specimens too. The conservatism is due to the use of an over-reduced shear area in these code equations, and increases with increasing number of bolt rows as the difference between the net and the active shear areas widens while the shear resistance becomes more important relative to the tensile resistance.

The equations specified in the current Australasian cold-formed steel structures code consistently and significantly overestimate the block shear capacities of all specimens tested in the present work. The major reason is the use of the gross area in computing the tensile or shear yielding resistance component of the block shear capacity.

The active shear resistance planes of a bolted connection block is identified in this paper, which is crucial for an accurate determination of the block shear capacity of a connection with multiple rows of bolts. The equation proposed for connections in cold-reduced steel sheets, which is based on the tensile rupture and shear yielding mechanism, and which makes use of an in-plane shear lag factor and the shear resistance planes identified in the present work, has been demonstrated to provide the most consistent and accurate results in predicting the block shear capacities of the tested specimens composed of G450 sheet steel. 


\section{Acknowledgments}

The authors would like to thank John Kralic, Manager, Lysaght Research \& Technology, Bluescope Steel Limited, for supplying the G450 sheet steel materials used in the present work. The authors thank Gregory Hancock, Emeritus Professor, The University of Sydney, for his expert input and for providing crucial references concerning the state-of-the-art of bolted connection design in cold-formed sheet steel. The authors also thank Chris Cook, Dean of Engineering, and Muhammad Hadi, head of the Advanced Structural Engineering and Construction Materials Group, both of the University of Wollongong, for supporting the laboratory tests that were conducted in the High Bay Lab of the Faculty of Engineering. The test specimens were fabricated by Ritchie McLean.

\section{References}

AISC (1978) Specification for the Design, Fabrication and Erection of Structural Steel for Buildings, American Institute of Steel Construction, Chicago IL.

AISC (1986) Load and Resistance Factor Design Specification for Structural Steel Buildings,

American Institute of Steel Construction, Chicago IL.

AISC (1989) Allowable Stress Design Specification for Structural Steel Buildings, American Institute of Steel Construction, Chicago IL.

AISC (1993a) Load and Resistance Factor Design Specification for Structural Steel

Buildings, American Institute of Steel Construction, Chicago IL.

AISC (1993b) Commentary on the Load and Resistance Factor Design Specification for

Structural Steel Buildings, American Institute of Steel Construction, Chicago IL.

AISC (1999) Load and Resistance Factor Design Specification for Structural Steel Buildings,

American Institute of Steel Construction, Chicago IL. 
AISC (2005a) Specification for Structural Steel Buildings, ANSI/AISC 360-05, American Institute of Steel Construction, Chicago IL.

AISC (2005b) Commentary on the Specification for Structural Steel Buildings, ANSI/AISC 360-05, American Institute of Steel Construction, Chicago IL.

AISC (2010a) Specification for Structural Steel Buildings, ANSI/AISC 360-10, American Institute of Steel Construction, Chicago IL.

AISC (2010b) Commentary on the Specification for Structural Steel Buildings, ANSI/AISC 360-10, American Institute of Steel Construction, Chicago IL.

AISI (2010) Supplement No. 2 to the North American Specification for the Design of Coldformed Steel Structural Members 2007 Edition, American Iron and Steel Institute, Washington DC.

Birkemoe, P.C., and Gilmor, M.I. (1978) "Behavior of bearing-critical double-angle beam connections.” Engineering Journal AISC, 15 (4), 109-115.

Chong, K. P., and Matlock, R. B. (1975) "Light-gage steel bolted connections without washers.” J. Struct. Div. ASCE, 101 (ST7), 1381-191.

Clements, D. D. A., and Teh, L. H. (2011) "Finite element investigations of behaviour and strength of bolted connections in cold-reduced steel sheets," in preparation.

Cunningham, T. J., Orbison, J. G., and Ziemian R. D. (1995) “Assessment of American block shear load capacity predictions." J. Construct. Steel Res., 35 (3), 323-338.

Driver, R. G., Grondin, G. Y., and Kulak, G. L. (2006) "Unified block shear equation for achieving consistent reliability.” J. Construct. Steel Res., 62 (3), 210-222.

ECS (1992) Eurocode 3: Design of steel structures, Part 1.8: Design of joints, EN 1993-1-8, European Committee for Standardisation, Brussels, Belgium.

ECS (2005) Eurocode 3: Design of steel structures, Part 1.8: Design of joints, EN 1993-1-8, European Committee for Standardisation, Brussels, Belgium. 
Epstein, H. I. (1996) "Effects of the latest LRFD block shear code change." Engineering Journal AISC, 33 (1), 30-33.

Epstein, H. I., and Aleksiewicz, L. J. (2008) "Block shear equations revisited ... Again." Engineering Journal AISC, 45 (1), 5-12.

Franchuk, C. R., Driver, R. G., and Grondin, G. Y. (2003) "Experimental investigation of block shear failure in coped steel beams." Can. J. Civ. Eng., 30, 871-881.

Hancock, G. J. (2007) Design of Cold-Formed Steel Structures, $4^{\text {th }}$ ed., Australian Steel Institute, Sydney.

Hardash, S. G., and Bjorhovde, R. (1985) "New design criteria for gusset plates in tension." Engineering Journal AISC, 22 (2), 77-94.

Huns, B. B. S., Grondin, G. Y., and Driver, R. G. (2006) “Tension and shear block failure of bolted gusset plates.” Can. J. Civil Engrg., 33, 395-408.

Kassar, M., and Yu, W. W. (1992) "Effect of strain rate on material properties of sheet steels." J. Struct. Eng., 118 (11), 3136-3150.

Kulak, G.L. and Grondin, G.Y. (2001) “AISC LRFD Rules for block shear in bolted connections - A review." Engineering Journal AISC, 38 (4), 199-202.

Kuwamura, H., and Isozaki, A. (2002) "Ultimate behaviour of fastener connections of thin stainless steel plates.” J. Struct. Construct. Eng. AIJ, 556, 159-166.

Ricles, J. M., and Yura, J. A. (1983) "Strength of double-row bolted web connections." J. Struct. Div. ASCE, 109 (ST1), 126-142.

Rogers, R. A., and Hancock, G. J. (1998) "Bolted connection tests of thin G550 and G300 sheet steels.” J. Struct. Eng., 124 (7), 798-808.

SA/SNZ (2005) Cold-Formed Steel Structures, AS/NZS 4600:2005, Standards Australia/Standards New Zealand. 
Seleim, S., and LaBoube, R.A. (1996) "Behavior of low ductility steels in cold-formed steel connections." Thin-Walled Structures, 25 (2), 135-150.

Teh, L. H., and Gilbert, B. P. (2011) "Net section tension capacity of bolted connections in cold-reduced steel sheets," submitted for publication in J. Struct. Eng., ASCE.

Teh, L. H., and Hancock, G. J. (2005) "Strength of welded connections in G450 sheet steels." J. Struct. Eng., 131 (10), 1561-1569.

Topkaya, C. (2004) "A finite element parametric study on block shear failure of steel tension members.” J. Construct. Steel Res., 60 (11), 1615-1635. 


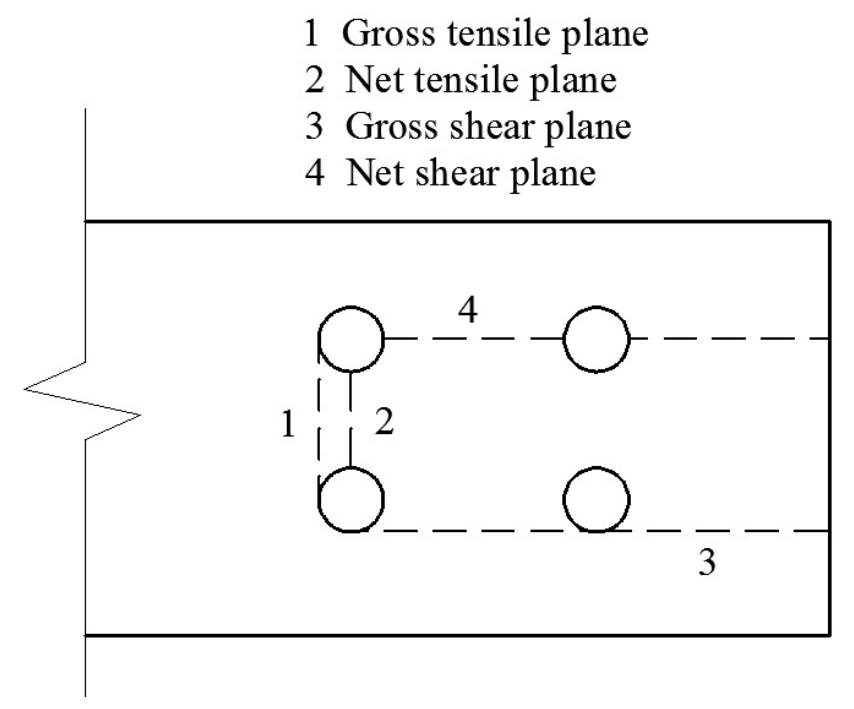

Figure 1 Code definitions of tensile and shear resistance planes

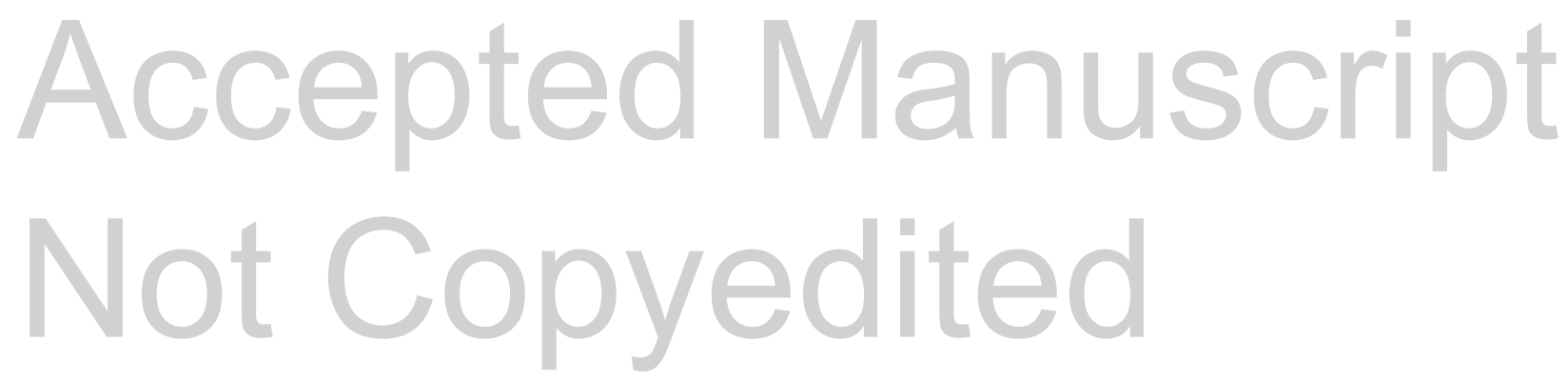




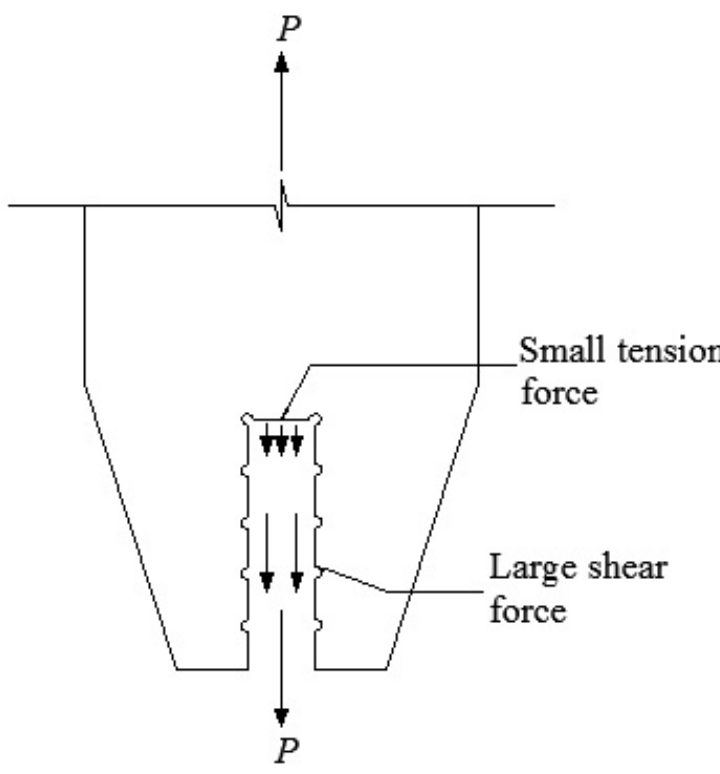

(a) High aspect ratio

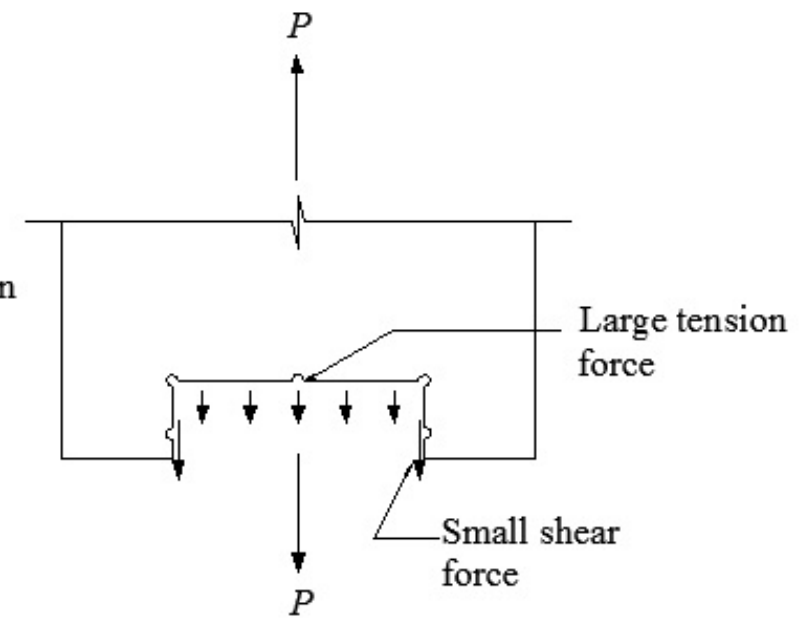

(b) Low aspect ratio

Figure 2 Tensile and shear resistance components against block shear failure

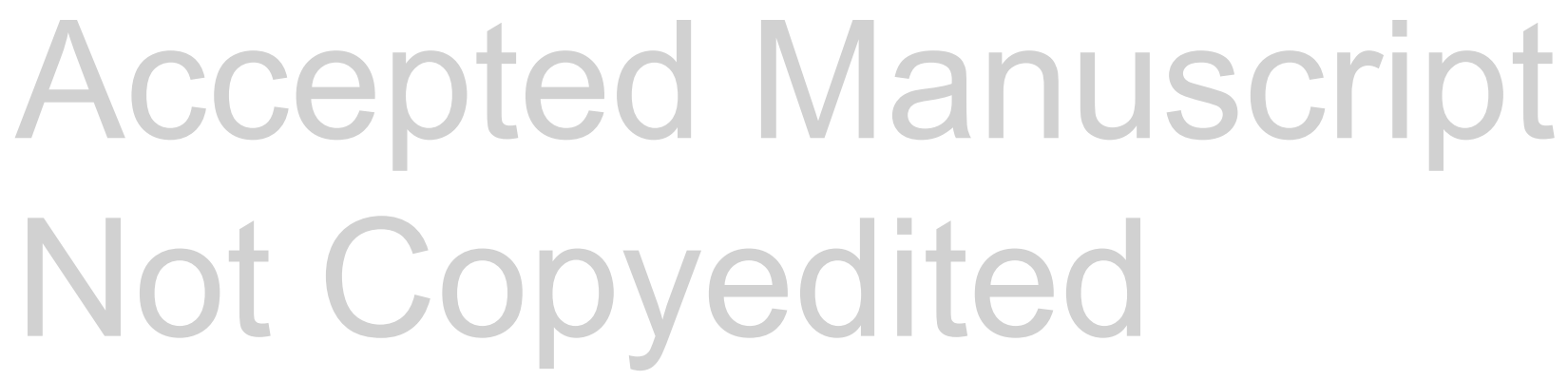


Figure 3

Journal of Structural Engineering. Submitted April 12, 2011; accepted August 2, 2011;

posted ahead of print August 5, 2011. doi:10.1061/(ASCE)ST.1943-541X.0000478

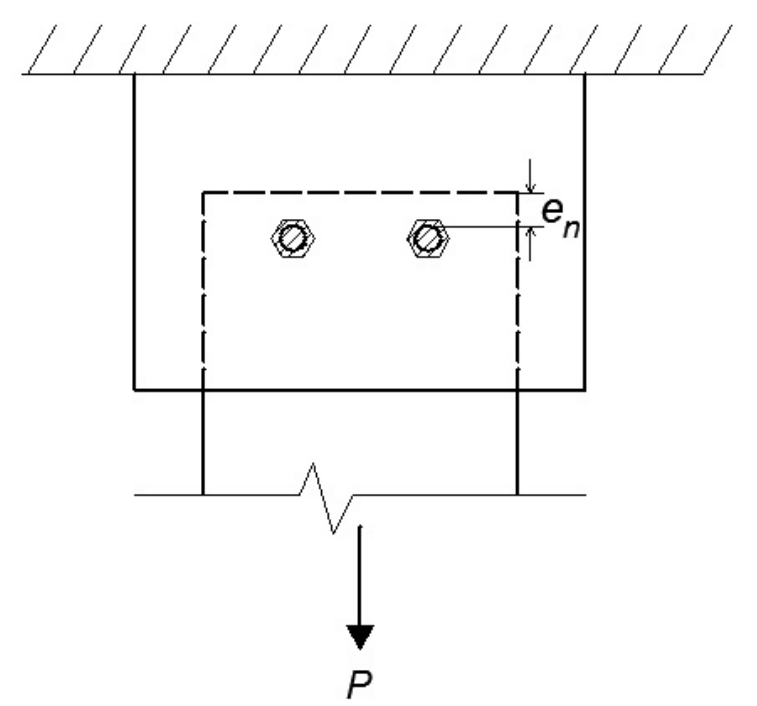

Figure 3 A two-bolt connection

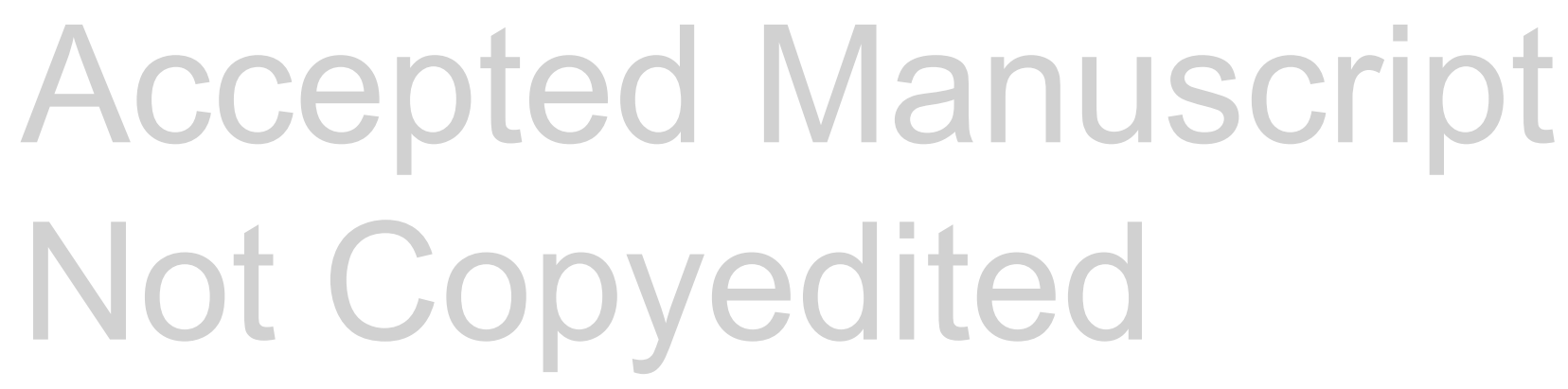




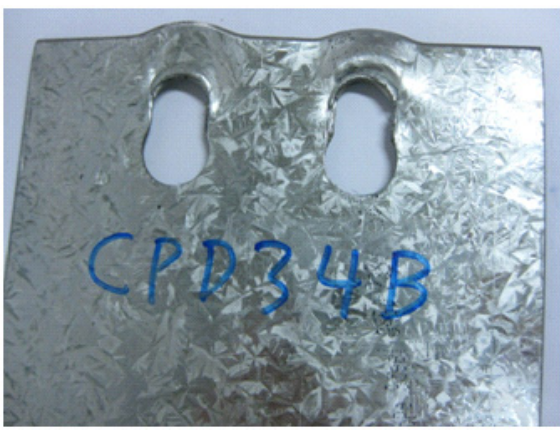

(a) Shear out failure

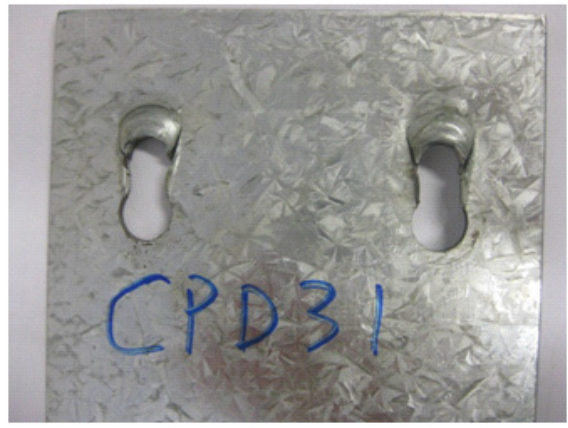

(b) Bearing failure

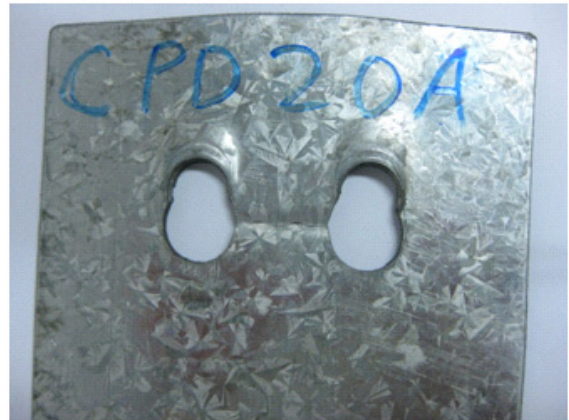

(c) Block shear failure

Figure 4 Various failure modes

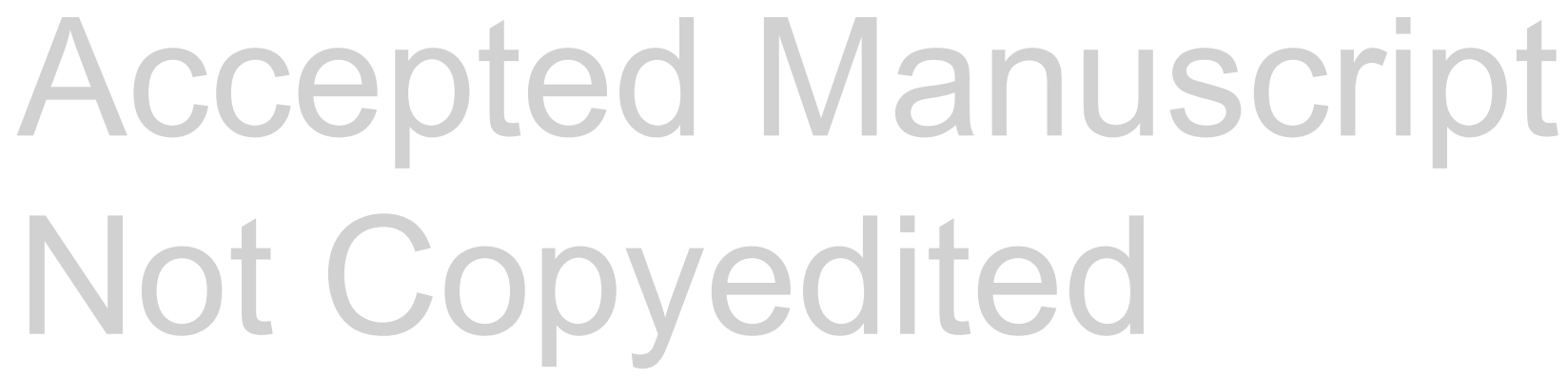


Figure 5

Journal of Structural Engineering. Submitted April 12, 2011; accepted August 2, 2011;

posted ahead of print August 5, 2011. doi:10.1061/(ASCE)ST.1943-541X.0000478

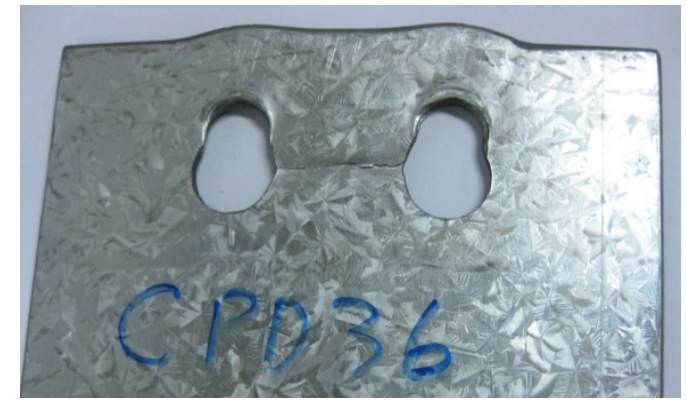

Figure 5 Shear-out deformations gave way to block shear failure

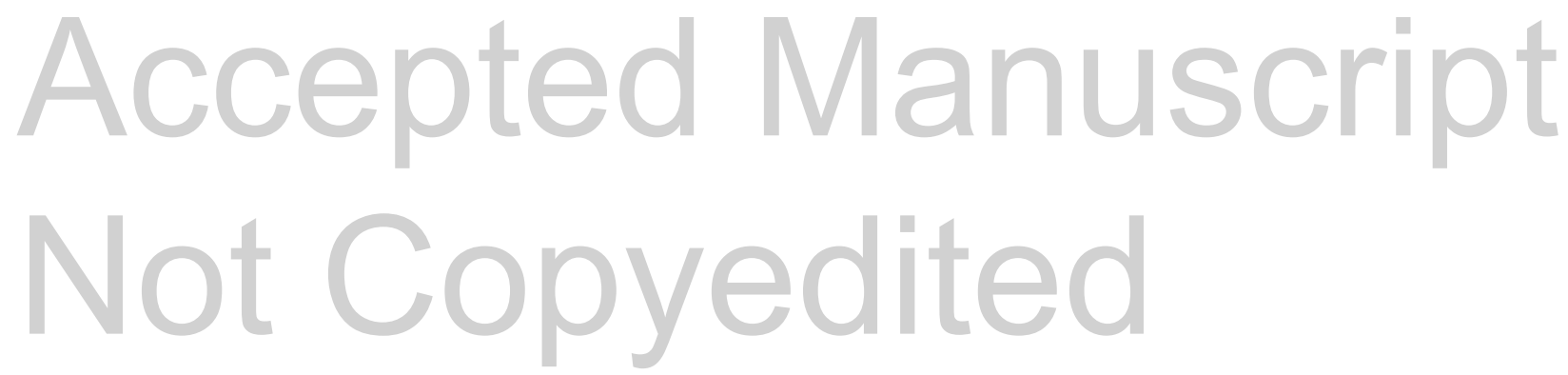




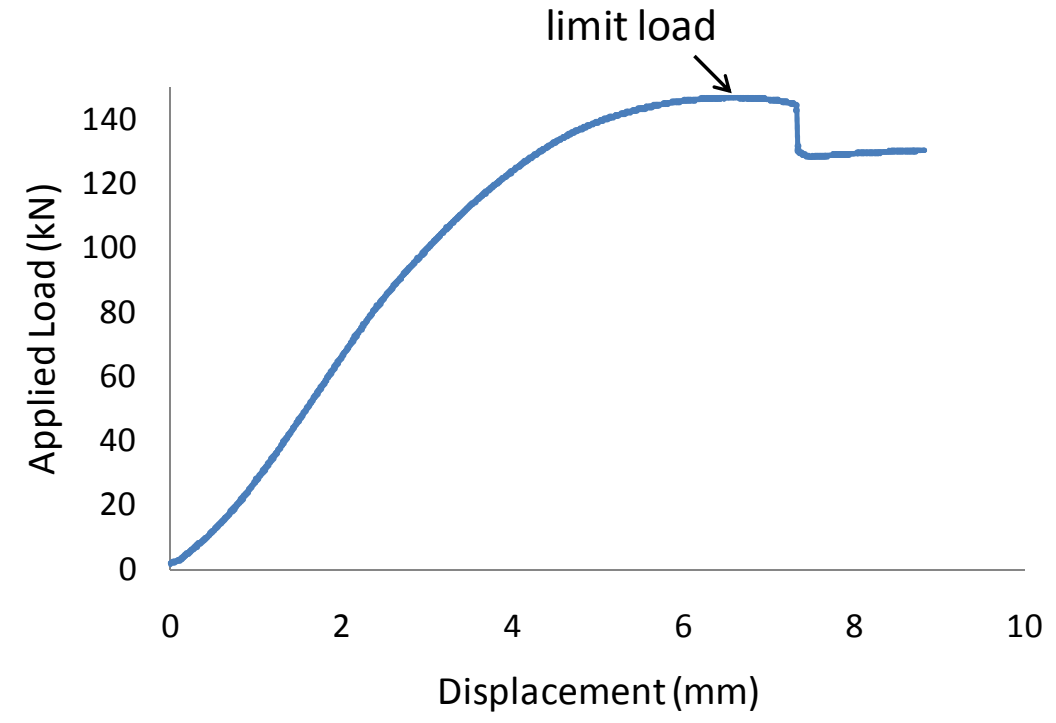

Figure 6 Definition of block shear capacity

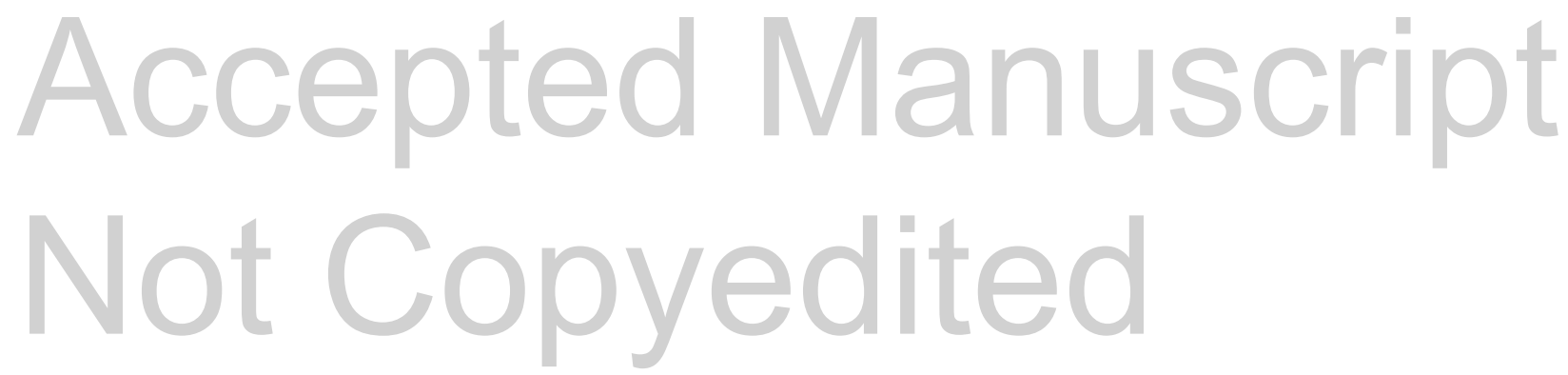




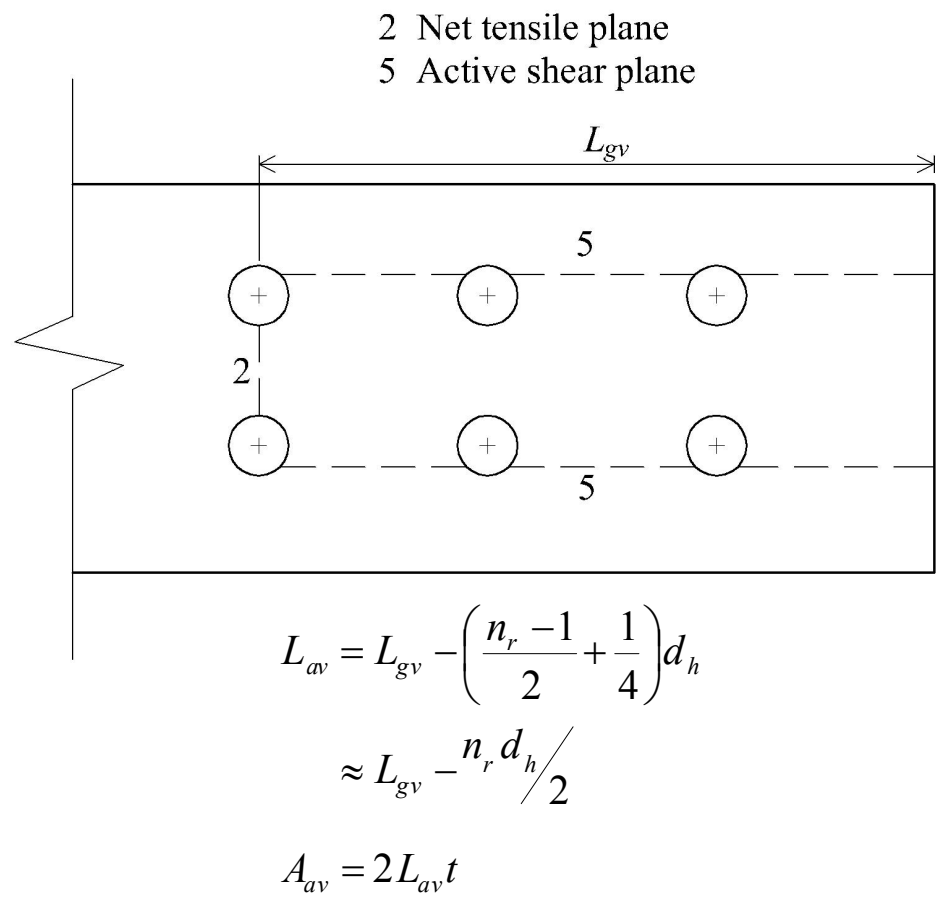

Figure 7 Tensile and shear resistance planes defined in the present work

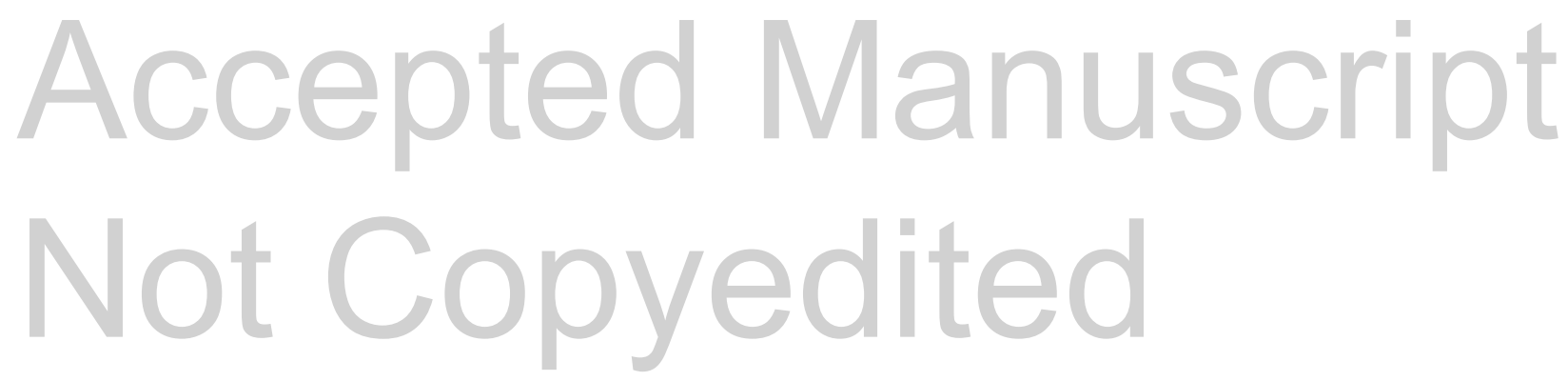




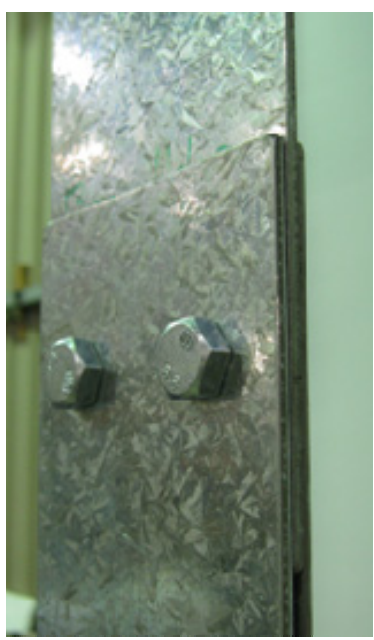

(a) Series A

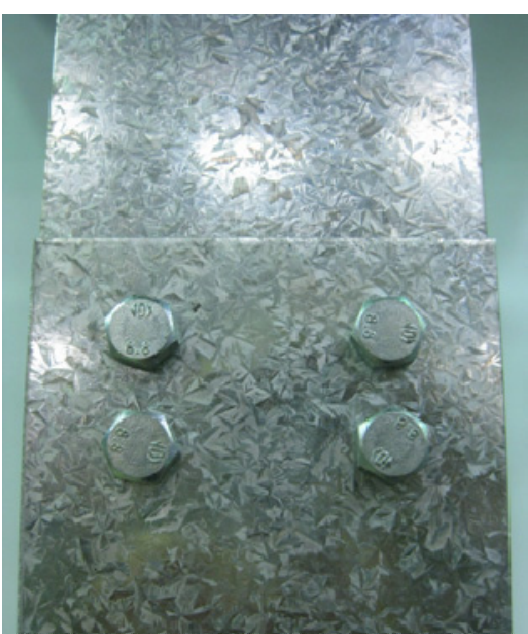

(b) Series B

Figure 8 Series A and B configurations

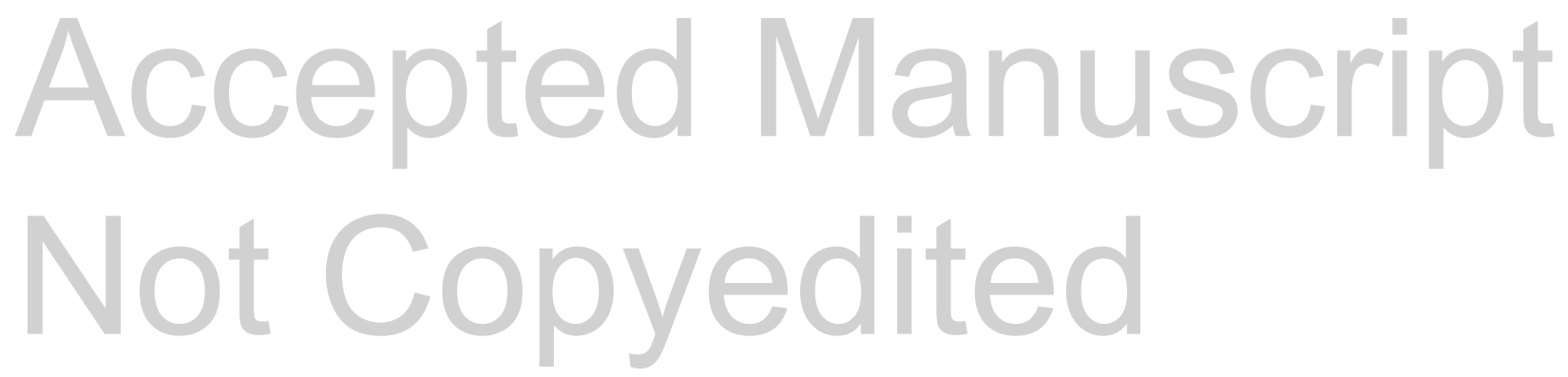




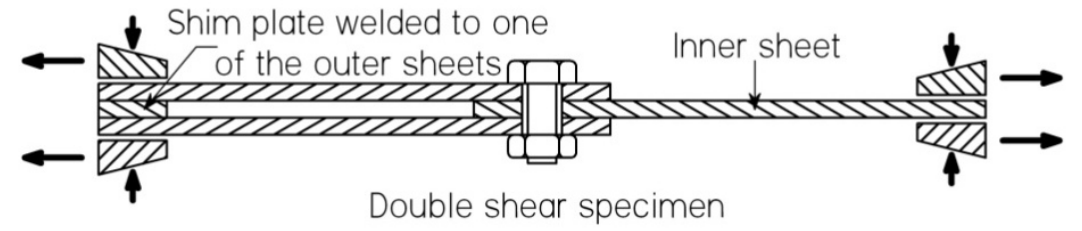

Figure 9 Concentric loading of critical component

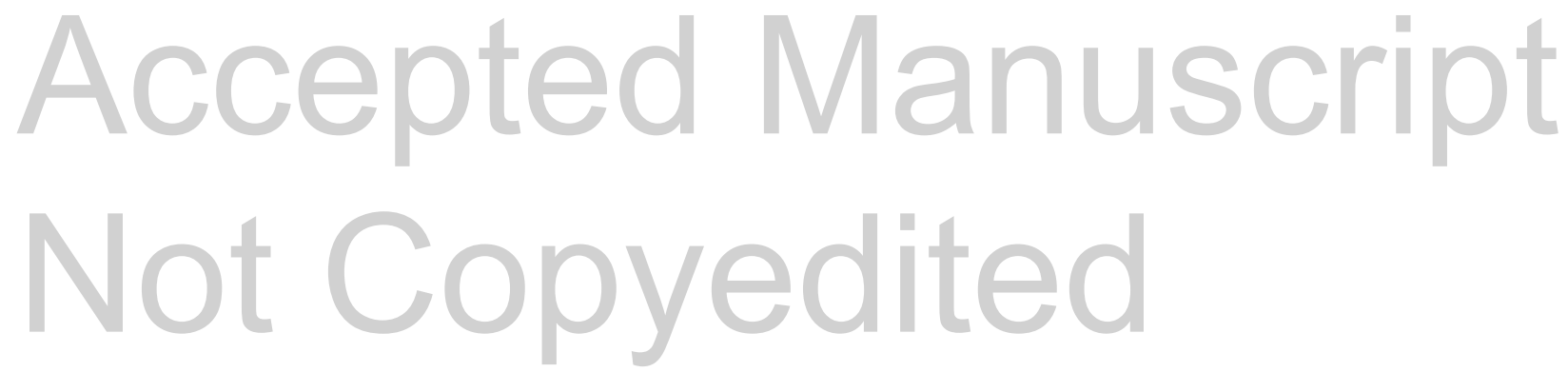




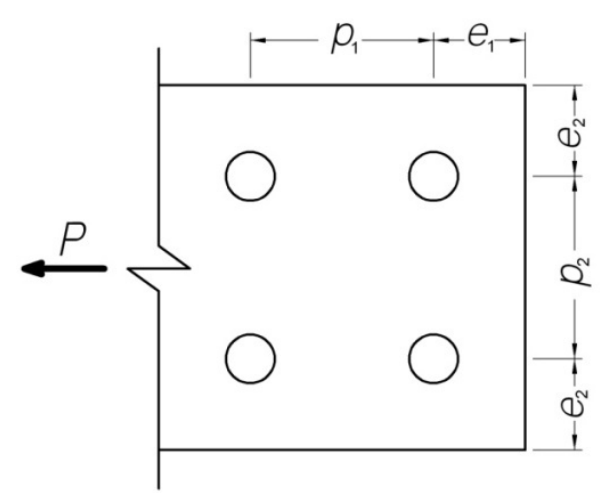

Figure 10 Geometric variables of a bolted connection

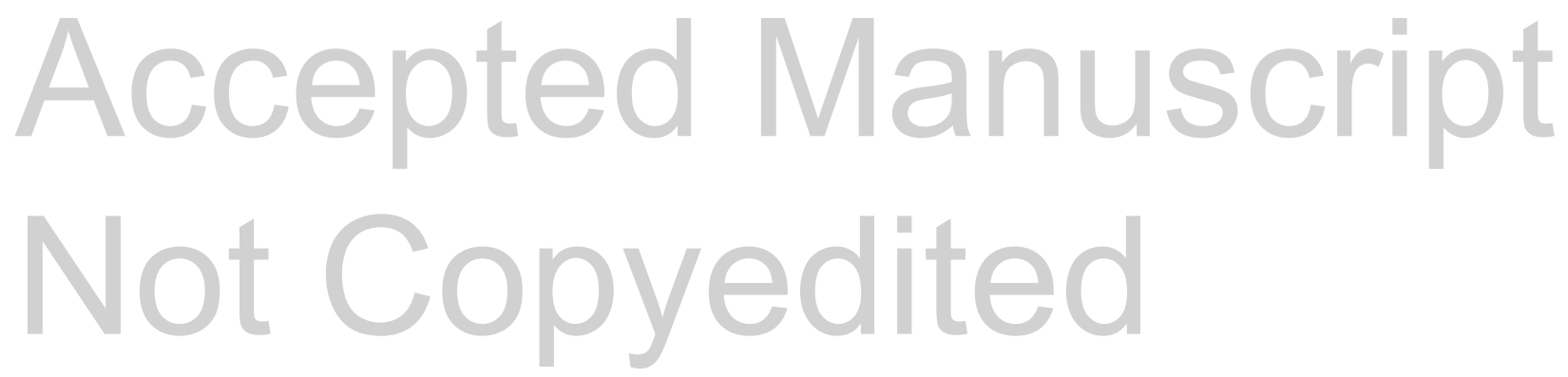

